\title{
No meio do caminho: o desenho geométrico e projetivo entre as "Duas Culturas"
}

\section{In the midway: the geometric and projective draw between the "Two Cultures"}

\author{
Beatriz dos Ramos Pinto \\ Professora do Colégio Pedro II, mestranda no Programa de Pós-Graduação em História \\ das Ciências e das Técnicas e Epistemologia (HCTE), \\ Universidade Federal do Rio de Janeiro (UFRJ). \\ bia_rp1@yahoo.com.br \\ orcid.org/0000-0002-3031-2406
}

\begin{abstract}
Resumo. O Desenho Geométrico e Projetivo se configura como uma área do conhecimento que transita entre as artes e a matemática.Perpassasaberes que se propõem dissociados entre si, dando ênfase à questão da interdisciplinaridade presente na produção do conhecimento humano, tantas vezes esquecida pelo pensamento científico Ocidental. Este artigo propõe um diálogo entre a questão da transitoriedade do Desenho Geométrico e Projetivo, nas áreas da Matemática e das Artes, com a questão da evolução do pensamento científico no Ocidente, mostrando como essa evolução interferiu diretamente na separação desses conhecimentos no currículo escolar.
\end{abstract}

Palavras-chave: Pensamento científico. Educação.Desenho. Matemática. Artes.

\begin{abstract}
Geometric and Projective Draw is configured as an area of knowledge that transitions between the arts and mathematics.Goes through knowledges dissocieteds, emphasizing the interdisciplinarity present in the production of human knowledge, so often overlooked by Western scientific thought. This article proposes a dialogue between the question of the transience of geometric and projective draw, in the areas of Mathematics and Arts, with the question of the evolution of scientific thought in the West, showing how this evolution directly interfered in the separation of these knowledge in the school curriculum.
\end{abstract}

Keywords:Scientific thinking. Education. Drawing. Mathematic. Art. 


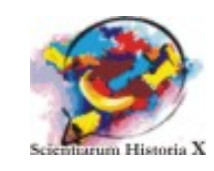

\section{Introdução}

Existe no cenário da educação Ocidental uma tendência por se segmentar o conhecimento em áreas pré-determinadas. Esta fragmentação, por consequência, gera reaçõesem cadeia que impactam, por fim, no currículo escolar.

Surgem, então,questões importantes para o estudo das disciplinas escolares, como, por exemplo, a fenda criada entre a Matemática e as Artes. De modo mais amplo, diga-se a separação entre Duas Culturas. Diante desse quadro, submerge o Desenho Geométrico e Projetivo - relegado por anos à falta de importância de seus conteúdos, enquanto disciplina escolar - como uma ponte entre universos distintos, para mostrar a necessidade de se olhar o conhecimento humano de forma integral.

Esta breve pesquisa procura delimitar a questão do Desenho e sua relação direta com as Artes e a Matemática, trazendo uma nova perspectiva para um velho problema: sua falta de definição curricular. Para abarcar o que propõe, o texto será dividido em três momentos que compreendem, respectivamente, a questão histórica e conceitual do tema, a questão central, que se limita geograficamente ao Brasil, e o resultado da pesquisa.

O primeiro momento do texto busca explicar o conceito de diferentes culturas científicas, apresentado por SNOW (1995) e revisitado por ROSA (2005). A seguir aponta para a peculiaridade existente no diálogo do Desenho com a Matemática e as Artes. Por fim, aponta para uma visão renovada do Desenho enquanto saber interdisciplinar.

\section{2. "Duas Culturas"?}

O termo entre "Duas Culturas" presente neste artigo foi apropriado do livro de ROSA (2005), que apresenta o problema gerado pela cisão histórica entre humanidades e ciências naturais, trazendo a necessidade de mostrar que ambas se relacionam por meio de uma linguagem comum "associada na tradição intelectual herdada dos gregos e do Iluminismo, atualizada ou transformadas pelas teorias contemporâneas.” (Idem, pg. 4243)

Há uma tendência na história da evolução do pensamento científico Ocidental por se determinar essa cisão (SNOW, 1995). A separação dos saberes foi criada a partir do Iluminismo. Antes todo saber era transdisciplinar. Nada se dissociava. Com a retomada e apropriação do conceito de taxonomia pelo método científico, as partes passam a ser não relativas, mas reais. Deste modo, o Ocidente passa a dissociar os saberes, colocando-os em caixas pré-programadas de conhecimento. Contudo essa dissociação mais prejudicou a evolução do pensamento do que ajudou, ao passo que não permite que se faça uma genealogia séria do conhecimento humano. 
Este esfacelamento está enraizado na física de Newton, que fez da ciência moderna uma ciência fragmentada, acarretando consequências para todos os aspectos da sociedade, incluindo a Educação, que está em questão aqui, conforme colocam BEBRENS e OLIARI (2007, pag. 59-60):

\begin{abstract}
O paradigma tradicional ou newtoniano-cartesiano levou a fragmentação do conhecimento e a supervalorização da visão racional. Nesse sentido, propôs a primazia da razão sobre a emoção, especialmente, para atender a coerência lógica nas teorias e a eliminação da imprecisão, da ambigüidade e da contradição dos discursos científicos. A fragmentação atingiu as Ciências e, por conseqüencia, a Educação, dividindo o conhecimento em áreas, cursos e disciplinas. As instituições, em especial as educacionais, passaram a ser organizadas em departamentos estanques, no qual emergem os especialistas, considerados pela sociedade como os detentores do saber. Neste processo reducionista, criam-se as especialidades em uma única área do conhecimento.
\end{abstract}

As duas culturas separadas pela peneirado paradigma tradicional (newtoniano cartesiano) que estão em pauta aqui, referem-se à Matemática e às Artes como ambiente que comporta outro saber que transita entre elas. A disposição das Artes e da Matemática em culturas diferentes é resultado desse processo de fragmentação. Essa visão reducionista gerou currículos estanques em que essas disciplinas são ensinadas como saberes que não dialogam entre si.

Tomas Kuhn aponta em seu livro - A estrutura das revoluções científicas - (1998, p. 212) para um caráter específico de uma revolução científica, que pressupõe uma alternância de paradigmas, tratando especificamente do que ocorreu após o paradigma newtoniano, em que a especialização cada vez maior diminui a capacidade de comunicação entre grupos de conhecimento. Deste padrão, que emerge da necessidade de alcançar a certeza de que um conhecimento é verdadeiro, surge a questão do critério de verdade (HESSEN, 2000, p. 23), que fomenta uma consequente enculturação dele.

Adiante este trabalho trata de mostrar o diálogo possível entre essas "Duas Culturas".

\title{
3. Desenho, Matemática e Artes
}

Transita entre a Matemática e as Artes, no que tange o currículo escolar, um outro saber, também dissociado dos demais, mas que consegue trazer à luz a questão da interdisciplinaridade do conhecimento humano, pois une, mesmo que inconscientemente, duas culturas separadas pela peneira do conhecimento científico. $\mathrm{O}$ Desenho Geométrico e Projetivo está, historicamente, ligado ao conteúdo curricular da Matemática (BRASIL, PCNs - Matemática, 1998), contudo, também é abraçado pelas Artes ((BRASIL, PCNs - Artes, 1998) como conteúdo curricular

(...) o ensino da geometria que valorize o artístico justifica-se pela possibilidade de despertar e desenvolver o senso estético, envolvendo simultaneamente, as quatro funções da consciência - sensação, 
pensamento, sentimento e intuição - considerando que toda vida emerge de um mesmo padrão e que sua existência tem uma condição de unidade com o universo e o criador. (SANTOS e ORMEZZANO, In: ARAÚUO, 2012, p. 34)

Justamente essa facilidade de acesso à saberes que se propõe dissociados o faz perder credibilidade no cenário da educação nacional e, como visto anteriormente, esse descrédito está mais ligado à história da teoria do conhecimento do que à uma escolha burocrática, de aspecto legal, haja vista que dentro do paradigma tradicional, newtoniano-cartesiano, aquilo que não possui definição especifica fica à margem. E como o Desenho Geométrico e Projetivo perdeu esta definição com a Lei 5.692 de 1971 (PINTO, 2013, p. 18), ele foi posto num limbo - fato reiterado pela Lei 9.394 de 1996 que agora se mostra como uma via de diálogo, assumindo caráter positivo na educação, como não ocorria antes.

KUHN (1998) e HESSEN (2000) afirmam que há uma alternância de paradigmas ao longo da história da teoria do conhecimento no Ocidente. Deste modo, é provável que as questões em voga sobre a necessidade de um saber interdisciplinar e da transdisciplinaridade do conhecimento estejam relacionadas à uma nova tendência, apontando para um novo paradigma que consiga abrir espaço para um diálogo verdadeiro entre os saberes. BEBRENS e OLIARI colocam que "a proposta da nova visão depende do avanço do paradigma da ciência que impulsiona a revisão do processo fragmentado do conhecimento na busca de reintegração do todo" (In: ARAÚJO, 2012, pag. 61).

Diante do advento de um novo paradigma, o Desenho Geométrico e Projetivo mostra estar um passo à frente, quando se trata da capacidade de dialogar. Repensar sua prática é fundamental para que ele não acabe por perder essa característica positiva que lhe foi imposta e se transmute em mais uma cultura.

\section{Retomar o diálogo}

A necessária brevidade deste artigo não possibilitou o esgotamento do assunto em questão, tendo se mostrado como ponto de partida para uma pesquisa mais profunda das relações da teoria do conhecimento com a educação escolar. Seguem os apontamentos que concluem o mesmo, reiterando o que foi apresentado até aqui.

Uma prova concreta de que nenhum saber se dissocia é o diálogo transdisciplinar existente entre as três áreas apresentadas. O Desenho Geométrico e Projetivo transita de forma natural entre conhecimentos separados e colocados em lugares completamente diferentes. Ele está nas Artes, no estudo da perspectiva, das projeções bidimensionais, no estudo da teoria da percepção visual, etc; está na matemática no estudo do das figuras planas, da geometria descritiva, no estudo da razão áurea, etc. E por estar no meio do caminho, acabou por ficar relegado à segundo plano no que tange a educação escolar.

Mas estar no meio do caminho seria um problema? 
Este artigo apontou para uma resposta negativa a esta pergunta, de modo que as necessidades que emergem da própria produção do conhecimento, conforme foi visto, apontam para o caminho que foi imposto ao Desenho Geométrico e Projetivo. Retomar o diálogo é necessário. E no que trata das relações entre Artes e Matemática, o Desenho é uma via.

Se todo conhecimento é produzido com base numa perspectiva humanizada do universo, e a percepção é uma vertente única, no sentido próprio do termo, insistir na fragmentação deste conhecimento implica desconsiderar as necessidades que emanam da própria sociedade que o produz. Portanto, essa retomada de diálogo entre saberes fragmentados vai além dos que foram colocados aqui e apontam para uma verdadeira transdisciplinaridade da educação, como consequência dessa mudança. Sabe-se que é possível, mas os caminhos ainda seguem escorregadios.O novo precisa romper com o velho para que as mudanças aconteçam.

Enquanto o conhecimento humano não for concebido de forma integral, a educação escolar não estará respondendo plenamente a sua função de formadora da sociedade e seguirá escrevendo um futuro desvinculado de questões importantes sobre este próprio conhecimento.

\section{Referências}

ARAÚJO, Ana Paula Batista. Memórias do Ensino de Desenho na UFPel: Da Escola de Belas Artes ao Centro de Artes. Dissertação de Mestrado, Pelotas: UFP, 2012.

BRASIL. Lei de Diretrizes e Bases da Educação Nacional, n 9.394, de 20 de dezembro de 1996.

BRASIL. Parâmetros Curriculares Nacionais (PCNs). Matemática.Brasília: MEC/SEF, 1998.

. Parâmetros Curriculares Nacionais (PCNs). Arte. Brasília: MEC/SEF, 1998.

HESSEN, Johannes. Teoria do Conhecimento. São Paulo: Martins Fontes, 2000.

KUHN, Thomas S. A estrutura das revoluções científicas. São Paulo: Perspectiva S. A., 1998. 
PINTO, Beatriz dos Ramos. O Desenho Geométrico e o currículo escolar: escola, atualidade e luta. (Monografia de conclusão de Especialização). Escola de Belas Artes - UFRJ, 2013.

ROSA, Luiz Pinguelli. Tecnociências e Humanidades: novos paradigmas, velhas questões. São Paulo: Paz e Terra, 2005.

SANTOS, Rosângela S.; ORMEZZANO, Graciela. Para além da geometria na escola: Antigas e novas abordagens. UPF editora. Passo Fundo, 2005.

SNOW, Cherles Percy. As duas culturas e uma segunda leitura: uma visão ampliada das Duas Culturas e a Revolução Científica. SP: EDUSP, 1995. 